\title{
Formability of Magnesium Alloys AZ80 and ZE10
}

\author{
T. Pasang ${ }^{a *}$, V. Satanin ${ }^{b}$, M. Ramezani ${ }^{\mathrm{c}}, \mathrm{M}$. Waseem ${ }^{\mathrm{d}}$, T. Neitzert ${ }^{\mathrm{e}}$ and \\ O. Kamiya ${ }^{\dagger}$ \\ ${ }^{a-e}$ Department of Mechanical Engineering \\ AUT University, Auckland - New Zealand 1020 \\ fDepartment of Mechanical Engineering, Akita University \\ 1-1 Tegatagakuen-machi, Akita, 010-8502, Japan

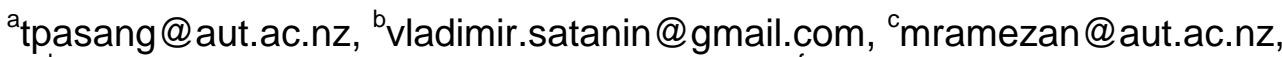 \\ 'mwaseem@aut.ac.nz, ${ }^{\mathrm{t} t n e i t z e r @ a u t . a c . n z, ~ ' k a m i y a @ g i p c . a k i t a-u . a c . j p ~}$ \\ *corresponding author
}

Keywords: Formability, magnesium alloys, AZ80, ZE10

\begin{abstract}
Formability of two magnesium alloys, namely, AZ80 and ZE10, has been investigated. Both alloys were supplied with a thickness of $0.8 \mathrm{~mm}$. The grain structure of the as-received AZ80 alloy showed dislocations, twins and second-phase particles and-/or precipitates distributed uniformly within grains. These were not obvious on the ZE10 alloy. The investigations were carried out at room temperature for both alloys in the as-received and heat treated conditions $\left(410^{\circ} \mathrm{C}\right.$ for 1 hour followed by water quench). The heat treatment significantly changed the grain structure of the AZ80 alloy, but did not affect the ZE10 alloy apart from grain enlargement. The formability was studied on the basis of plastic strain ratio (r) and strain hardening coefficient (n) by means of tensile testing. In the as-received condition, the ZE10 alloy had a slightly better formability $(r \times n)$ than AZ80 alloy. Following heat treatment, however, the formability of the AZ80 alloy was improved significantly (by about 26\%), while the ZE10 alloy did not show any significant change.
\end{abstract}

\section{Introduction}

Magnesium alloys offer a high strength-to-weight-ratio, and is therefore very attractive for the automotive and aerospace industries. Applications of magnesium alloys will result in weight reduction and, hence, decrease fuel consumption and $\mathrm{CO}_{2}$ emission. Components made of magnesium alloys are mainly produced by die casting, because it enables manufacturing the components with complex geometry. The mechanical properties of these parts such as ductility and strength are, however, relatively low. In addition, die casting is not ideal for producing thin wall structures due to large amount of waste material [1,2]. This may be overcome by sheet metal forming which possess advantageous mechanical properties and fine-grained microstructure [2]. However, the application of sheet metal forming technologies of magnesium alloys has its own challenges with their low formability at room temperature. The reason for this is that magnesium alloys have a HCP crystal structure with only two active and independent base slip systems and a relatively strong texture owing to their process rolling history, which allow only limited deformation [2]. Improvement of formability can be achieved by increasing the forming temperature and by applying appropriate heat treatments prior to forming $[2,3,4]$. Various studies on formability of magnesium alloys have been performed at room temperature and elevated temperatures. Stutz et al. [5] studied the effect of texture on the formability of ZE10 and AZ31. Both materials were in the annealed condition. They concluded that ZE10 had a better formability than AZ31 due to a favourable distribution of basal planes. Moreover, from the forming limit diagrams, they suggested that a forming temperature as high as $150^{\circ} \mathrm{C}$ is sufficient to obtain a competitive formability. Another study on the effect of texture on formability of magnesium alloys was conducted by Yi et al. [6]. They investigated the deep drawing behaviour of AZ31 and ZE10 sheets at temperatures 
between 100 and $300^{\circ} \mathrm{C}$. Due to the weaker texture of ZE10 alloys, it showed good deep drawing ability at $150^{\circ} \mathrm{C}$, compared to $200^{\circ} \mathrm{C}$ for the AZ31 alloy. Bohlen et al. [7] also studied the effect of texture of rare earth (RE) elements-containing alloys, e.g. ZK10, ZE10, ZEK100, ZEK410 and ZW41 and compared them with conventional alloys such as AZ31 and ZM21. They suggested that the RE elements successfully modified and weakened the RE-containing alloys leading to better formability. The addition of RE metals improves ductility, formability, creep and corrosion resistance of the alloys $[1,5,8,9]$. Boba et al. [10] investigated formability of AZ31B and ZEK100 by measuring the height of domes produced with hemispherical punch and dies at temperature up to $300^{\circ} \mathrm{C}$. The formability of both alloys was fairly limited at room temperature, but was generally improved with temperature, and reached the maximum formability at temperatures between 250 and $300^{\circ} \mathrm{C}$. They also suggested that, in general, the ZEK100 showed better formability than AZ31B. Formability by means of deep drawing was conducted by Doege and Dröder [2]. Following an investigation on AZ31B, AZ61B and M1, they concluded that these alloys have better a formability at a temperature range of 200 and $250^{\circ} \mathrm{C}$.

In this study, the formability of two magnesium alloys, namely, AZ80 and ZE10 sheets was investigated at room temperature in the as-received and heat treated conditions. Formability studies at elevated temperatures are being undertaken and will not be reported in this paper. Formability was assessed on the basis of plastic strain ratio (r) and strain hardening coefficient (n) from extensive tensile testing. The effect of microstructure was also analysed.

\section{Experimental Procedures}

Materials. Two different magnesium alloys with a thickness of $0.8 \mathrm{~mm}$ were used in this investigation. They were AZ80 and ZE10 alloys. AZ80 is a medium strength alloy with good forging capability, excellent machinability and comparatively low price, while ZE10 is characterised by high ductility and medium strength. The nominal compositions of these two alloys are presented in Table 1. Heat treatment was also performed on both alloys at $410^{\circ} \mathrm{C}$ for 1 hour, followed by water quench to compare the formability in the as-received and heat treated condition.

Table 1. Nominal composition of AZ80 and ZE10 alloys

\begin{tabular}{|c|c|c|c|c|}
\hline Alloy/Elements & $\mathrm{Al}$ & $\mathrm{Zn}$ & $\mathrm{RE}$ & $\mathrm{Mg}$ \\
\hline $\mathrm{AZ80}$ & 8.0 & 0.5 & - & Bal. \\
\hline ZE10 & - & 1.0 & $\mathrm{Ce}$ and La $<1.0$ & Bal. \\
\hline
\end{tabular}

Mechanical testing. In this study, formability was estimated on the basis of strain hardening exponent (n) and plastic strain ratio (r). In order to estimate these values, uniaxial tensile tests in three directions were performed, (i) along the rolling direction (RD) or $0^{\circ}$, (ii) $45^{\circ}$, and (iii) across the rolling direction or $90^{\circ}$. Three samples were tested for each condition. All the tests were performed at room temperature with a crosshead speed of $2.5 \mathrm{~mm} / \mathrm{min}$. Dog bones for tensile testing (Fig. 1) where prepared according to ASTM E646-07 "Standard Test Method for Tensile StrainHardening Exponents (n) of Metallic Sheet Materials" [11.] and ASTM E517-00 "Standard Test Method for Plastic Strain Ratio (r) for Sheet Metal" standards [12].
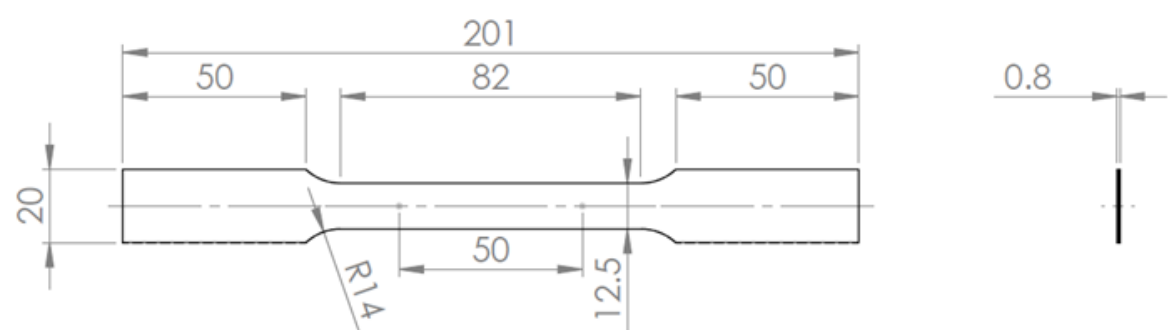

Fig. 1 Tensile test sample according to ASTM E517-00 and ASTM E646-07 standards 
The strain hardening exponent (n) was calculated using the following formula:

$$
\sigma_{t}=K \varepsilon_{t}^{n}
$$

where $\sigma_{\mathrm{t}}$ is true stress, $\mathrm{K}$ is strength coefficient, $\varepsilon_{\mathrm{t}}$ is true strain and $\mathrm{n}$ is strain hardening exponent. Both $\sigma_{\mathrm{t}}$ and $\varepsilon_{\mathrm{t}}$ can be calculated using the following formulae.

$$
\begin{aligned}
& \sigma_{t}=\sigma(1+\varepsilon) \\
& \varepsilon_{t}=\ln (1+\varepsilon)
\end{aligned}
$$

where $\sigma$ is engineering stress and $\varepsilon$ is engineering strain.

For each test, seven data points were measured above the yield point up to the ultimate strength point. The plastic strain ratio (r) was calculated using the following formula:

$$
r=\frac{\ln \left(w_{0} / w_{f}\right)}{\ln \left(l_{f} w_{f} / l_{0} w_{0}\right)}
$$

where $\mathrm{w}_{0}$ and $\mathrm{w}_{\mathrm{f}}$ are initial and final width of the specimen, respectively, while $l_{0}$ and $l_{\mathrm{f}}$ are initial and final gage lengths, respectively.

The measurement of plastic strain ratio was taken at 3\% strain for AZ80 and 9\% strain for ZE10. These were based on our preliminary tests which indicated that AZ80 and ZE10 had a minimum elongation of $5.6 \%$ and $10 \%$, respectively.

To determine the formability, the average $r$ and $n$ values where calculated by the following formula:

$$
\bar{r} \times \bar{n}=\frac{(r \times n)_{0}+(r \times n)_{90}+2(r \times n)_{45}}{4}
$$

Microscopy and Hardness Measurements. Standard metallography sample preparation was used with the following sequence: grinding (up to $2400 \mathrm{SiC}$ grid-paper), polishing and etching. The etchant used was a mixture of $10 \mathrm{ml}$ distilled water, $10 \mathrm{ml}$ glacial acetic acid, $4.2 \mathrm{~g}$ picric acid, and $70 \mathrm{ml}$ ethanol. The etched samples were then observed under an optical microscope (OM) and a scanning electron microscope (SEM). Microhardness was measured with a Vickers hardness tester with a load of $300 \mathrm{~g}$. The fracture surfaces from tensile testing were examined using an SEM.

\section{Results and Discussions}

Microstructures. Micrographs from optical microscopy and scanning electron microscopy of AZ80 and ZE10 alloys in the as-received conditions are presented in Figs. 2 and 3.
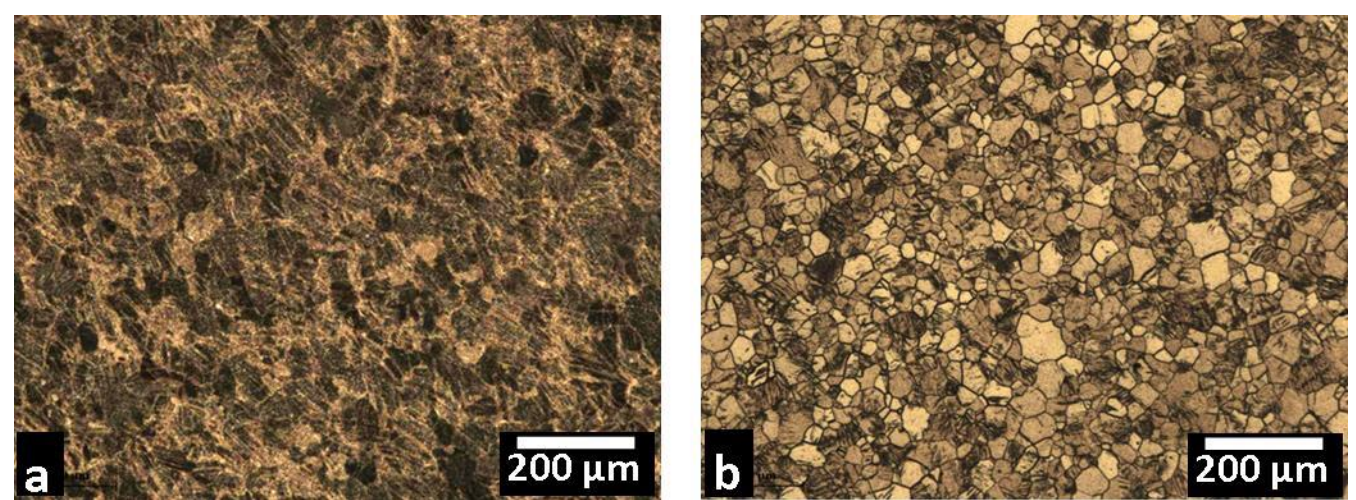

Fig. 2. Optical micrographs of the as-received materials showing microstructures of (a) AZ80, and (b) ZE10 

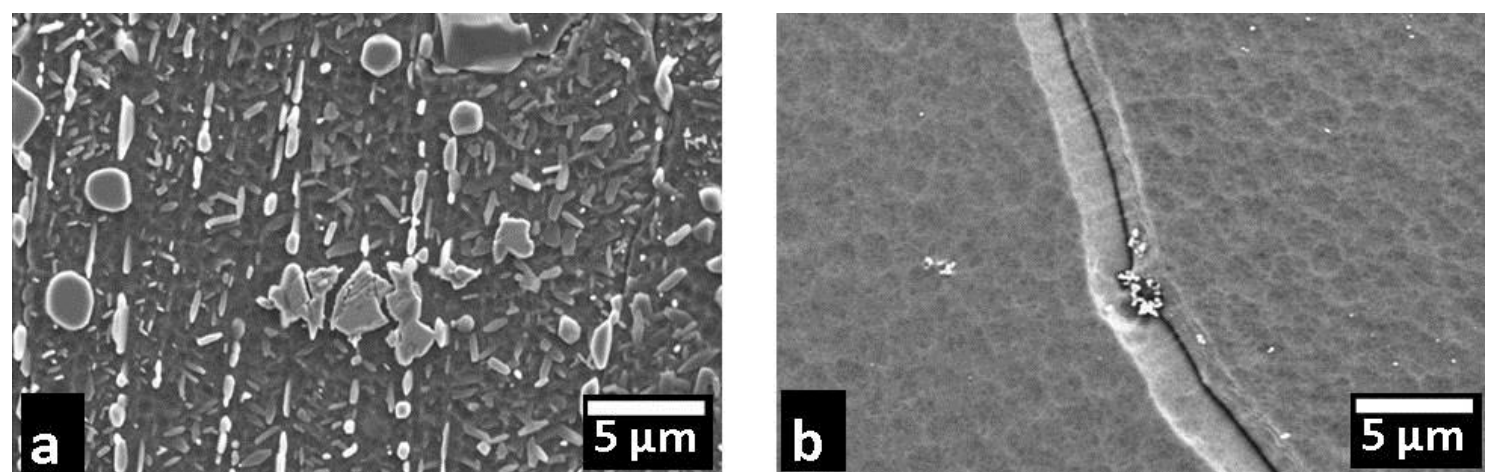

Fig. 3. Scanning electron micrographs of the as-received materials showing grain structures of (a) AZ80, and (b) ZE10

From Figs. 2 and 3, it can be seen that both materials were supplied in different conditions. The AZ80 was likely to be in the as-rolled condition, while ZE10 was in an annealed condition. AZ80 shows the presence of deformation bands and twins (Fig. 2a) as well as various types of precipitates (Fig. 3a), while ZE10 had equiaxed grains without evidence of deformation and/or precipitates (Figs. $2 b$ and $3 b)$.

On the heat treated samples, fairly significant changes were evident. For AZ80, the deformation bands, twins and /or precipitates have disappeared (Figs. 4a and 5a). Grain enlargement (Fig. 4b) as well as clean grain structure was observed on the heat treated ZE10 (Figs. 4b and 5b).
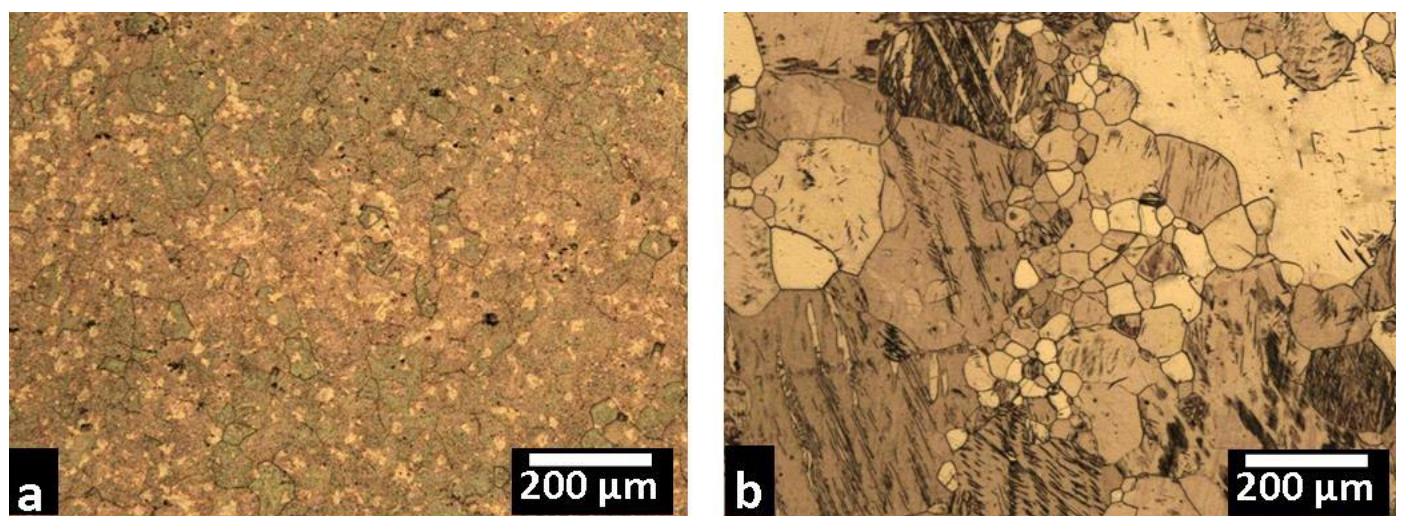

Fig. 4. Optical micrographs of heat treated materials showing microstructures of (a) AZ80, and (b) ZE10
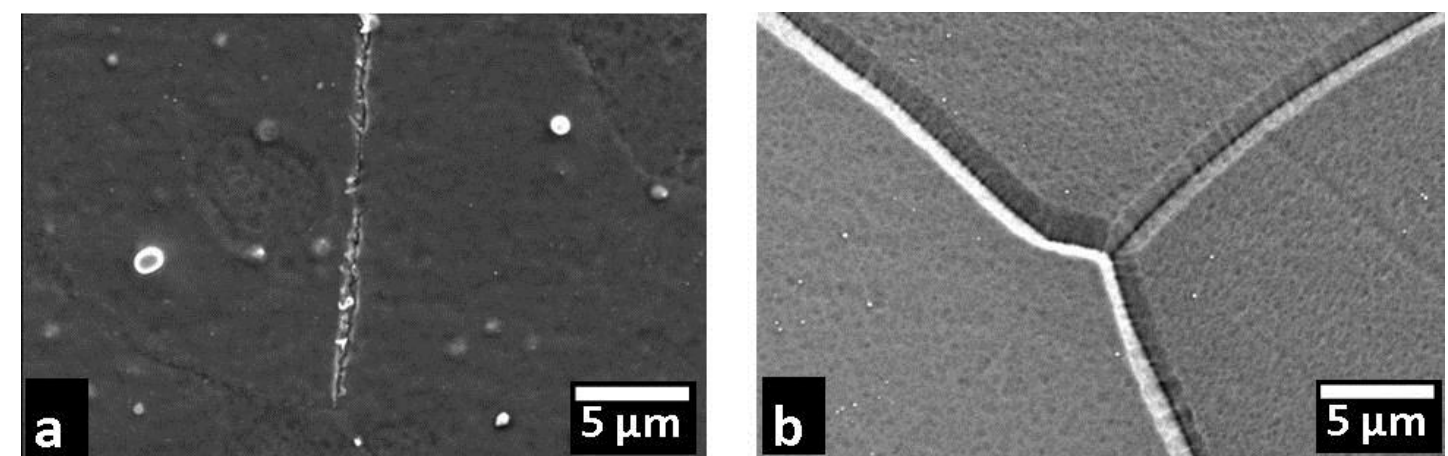

Fig. 5. Scanning electron micrographs of the heat treated materials showing grain structures of (a) AZ80, and (b) ZE10

Mechanical Properties. Comparison of mechanical properties of both materials in the as-received and heat treated conditions are presented in Table 2. 
Table 2. Mechanical properties of AZ80 and ZE10 in the as-received and heat treated conditions of samples from three different directions $\left(0^{\circ}, 45^{\circ}\right.$ and $\left.90^{\circ}\right)$

\begin{tabular}{|c|c|c|c|c|c|c|c|c|c|c|c|c|c|}
\hline $\begin{array}{c}\text { Materials } \\
\text { condition }\end{array}$ & \multicolumn{3}{|c|}{$\begin{array}{c}\text { Yield } \\
\text { Strength } \\
(\mathrm{MPa})\end{array}$} & \multicolumn{3}{c|}{$\begin{array}{c}\text { Ultimate } \\
\text { Strength } \\
(\mathrm{MPa})\end{array}$} & \multicolumn{3}{c|}{$\begin{array}{c}\text { Elongation } \\
(\%)\end{array}$} & \multicolumn{3}{c|}{$\begin{array}{c}\text { Stiffness } \\
(\mathrm{GPa})\end{array}$} & $\begin{array}{c}\text { Hardness } \\
(\mathrm{HV})\end{array}$ \\
\hline $\begin{array}{c}\text { AZ80 } \\
\text { as received }\end{array}$ & 219 & 226 & 241 & 330 & 318 & 328 & 10 & 7 & 6 & 44 & 58 & 46 & 98 \\
\hline $\begin{array}{c}\text { AZ80 } \\
\text { heat treated }\end{array}$ & 196 & 200 & 205 & 299 & 302 & 300 & 16 & 16 & 14 & 24 & 24 & 30 & 69 \\
\hline $\begin{array}{c}\text { ZE10 } \\
\text { as received }\end{array}$ & 161 & 141 & 129 & 193 & 187 & 185 & 24 & 25 & 22 & 2 & 2 & 2 & 44 \\
\hline $\begin{array}{c}\text { ZE10 } \\
\text { heat treated }\end{array}$ & 154 & 140 & 131 & 192 & 188 & 191 & 23 & 26 & 23 & 2 & 2 & 2 & 45 \\
\hline
\end{tabular}

Data in Table 2 indicates that the as-received AZ80 material had comparable ultimate strength in $0^{\circ}$ and $90^{\circ}$ rolling direction and marginally lower at $45^{\circ}$. The yield strength decreases from $90^{\circ}$ to $0^{\circ}$, while the elongation increased from $90^{\circ}$ to $0^{\circ}$. The highest stiffness for AZ80 was recorded in $45^{\circ}$ direction. Following heat treatment, both the yield and ultimate strength decreased between 6 to $17 \%$ while the ductility (elongation) was increased significantly i.e. by $60 \%, 128 \%$ and $133 \%$ in $0^{\circ}$, $45^{\circ}$ and $90^{\circ}$ directions, respectively. The lower strengths and higher elongation in the heat treated samples were associated with the disappearance of both the deformed grains (hence, high amount of dislocations and twins) and the precipitates (Figs 2a, 3a, 4a and 5a).

For the ZE10 alloy, the strengths for the as-received materials were higher in the $0^{\circ}$ direction compared to both $45^{\circ}$ and $90^{\circ}$ directions, while stiffness remained the same. The elongation on the ZE10 was marginally higher in the $45^{\circ}$ direction compared to both $0^{\circ}$ and $90^{\circ}$ directions. The heat treatment process, however, did not affect the properties significantly as it did on the AZ80 alloy. The grain structures were also similar (between the as-received and heat treated conditions) except for an increase in grain size at various locations.

Formability. Comparison of formability represented by strain hardening coefficient (n) and plastic strain ratio (r) is given in Tables 3 and 4. A direct comparison of formability between the two alloys in the as-received condition should be avoided since they were arguably supplied in different conditions. Furthermore, it should also be noted that the plastic strain ratio was measured at different strains for each material since they fractured at different elongations.

From Tables 3 and 4, it can be reported that the formability of AZ80 alloy increased by 25\% after heat treatment, even though the strain hardening exponent (n) was not affected. The heat treatment has positive impact on formability of the AZ80 alloy. This is supported by the higher elongation (hence, higher ductility) after heat treatment caused by the dissolution of precipitates, decreasing the number of twins and dislocations. For ZE10, the effect of heat treatment was not evident. The explanation is most likely the as-received material was already annealed as the grains were equiaxed (Fig. 2b) and there was no clear evidence of the presence of precipitates (Fig. 3b). Therefore, heat treatment at $410^{\circ} \mathrm{C} / 1 \mathrm{~h}$ followed by water quenching did not have a significant effect on the alreadyannealed material. 
Table 3. Strain hardening exponent (n) and plastic strain ratio (r) values of samples from three different directions $\left(0^{\circ}, 45^{\circ}\right.$ and $\left.90^{\circ}\right)$

\begin{tabular}{|c|c|c|c|c|c|c|c|c|c|}
\hline & \multicolumn{3}{|c|}{$\mathbf{n}$} & \multicolumn{3}{c|}{$\mathbf{r}^{*}$} & \multicolumn{3}{c|}{ r $\mathbf{~ n}$} \\
\hline & $\mathbf{0}^{\circ}$ & $\mathbf{4 5}^{\circ}$ & $\mathbf{9 0}^{\circ}$ & $\mathbf{0}^{\circ}$ & $\mathbf{4 5}^{\circ}$ & $\mathbf{9 0}^{\circ}$ & $\mathbf{0}^{\circ}$ & $\mathbf{4 5}^{\circ}$ & $\mathbf{9 0}^{\circ}$ \\
\hline AZ80-as received & 0.19 & 0.19 & 0.18 & 1.14 & 1.36 & 1.21 & 0.22 & 0.27 & 0.21 \\
\hline AZ80-heat treated & 0.20 & 0.20 & 0.18 & 1.41 & 1.56 & 1.67 & 0.29 & 0.31 & 0.30 \\
\hline & & & & \multicolumn{3}{|c|}{$\mathbf{r}^{* *}$} & & & \\
\hline ZE10-as received & 0.24 & 0.31 & 0.38 & 0.87 & 0.99 & 0.68 & 0.21 & 0.31 & 0.26 \\
\hline ZE10-heat treated & 0.26 & 0.32 & 0.36 & 0.83 & 1.00 & 0.75 & 0.22 & 0.32 & 0.27 \\
\hline
\end{tabular}

* r measured at $3 \%$ strain

$* * \mathrm{r}$ measured at $9 \%$ strain

Table 4. $\bar{n}$ and $\bar{r}$ values of samples from three different directions $\left(0^{\circ}, 45^{\circ}\right.$ and $\left.90^{\circ}\right)$

\begin{tabular}{|c|c|c|c|}
\hline & $\bar{n}$ & $\bar{r}$ & $\bar{r} \times \bar{n}$ \\
\hline AZ80-as received & 0.19 & 1.26 & 0.24 \\
\hline AZ80-heat treated & 0.19 & 1.55 & 0.30 \\
\hline & & & \\
\hline ZE10-as received & 0.31 & 0.89 & 0.27 \\
\hline ZE10-heat treated & 0.32 & 0.89 & 0.28 \\
\hline
\end{tabular}

The SEM micrographs of the tensile tested AZ80 samples showed dimples on all fracture surfaces. There were no obvious differences among all the three directions on either the as-received of heat treated conditions. However, by comparing the fracture surfaces of the as-received and heat treated samples, one would notice a larger and somewhat deeper dimples of the heat treated samples (Fig. 6). This indicates the slightly more ductile samples in the heat treated condition. For ZE10 samples, the SEM images in Fig. 7 show relatively equal size dimples suggesting comparable ductility between the as-received and heat treated materials.

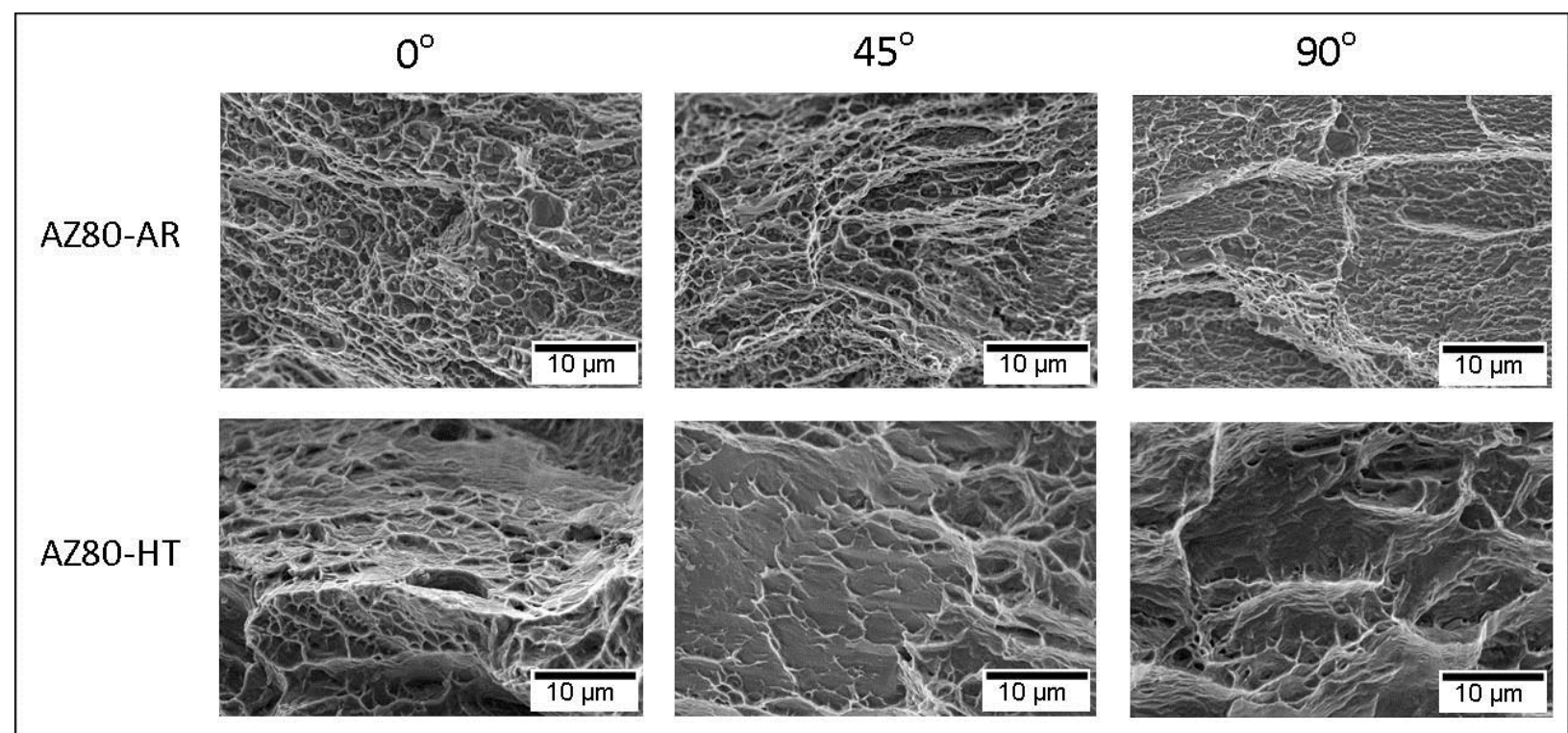

Fig. 6. Fracture surfaces of tensile tested samples of AZ80 materials in the as-received (AR) and heat treated (HT) conditions for three directions 


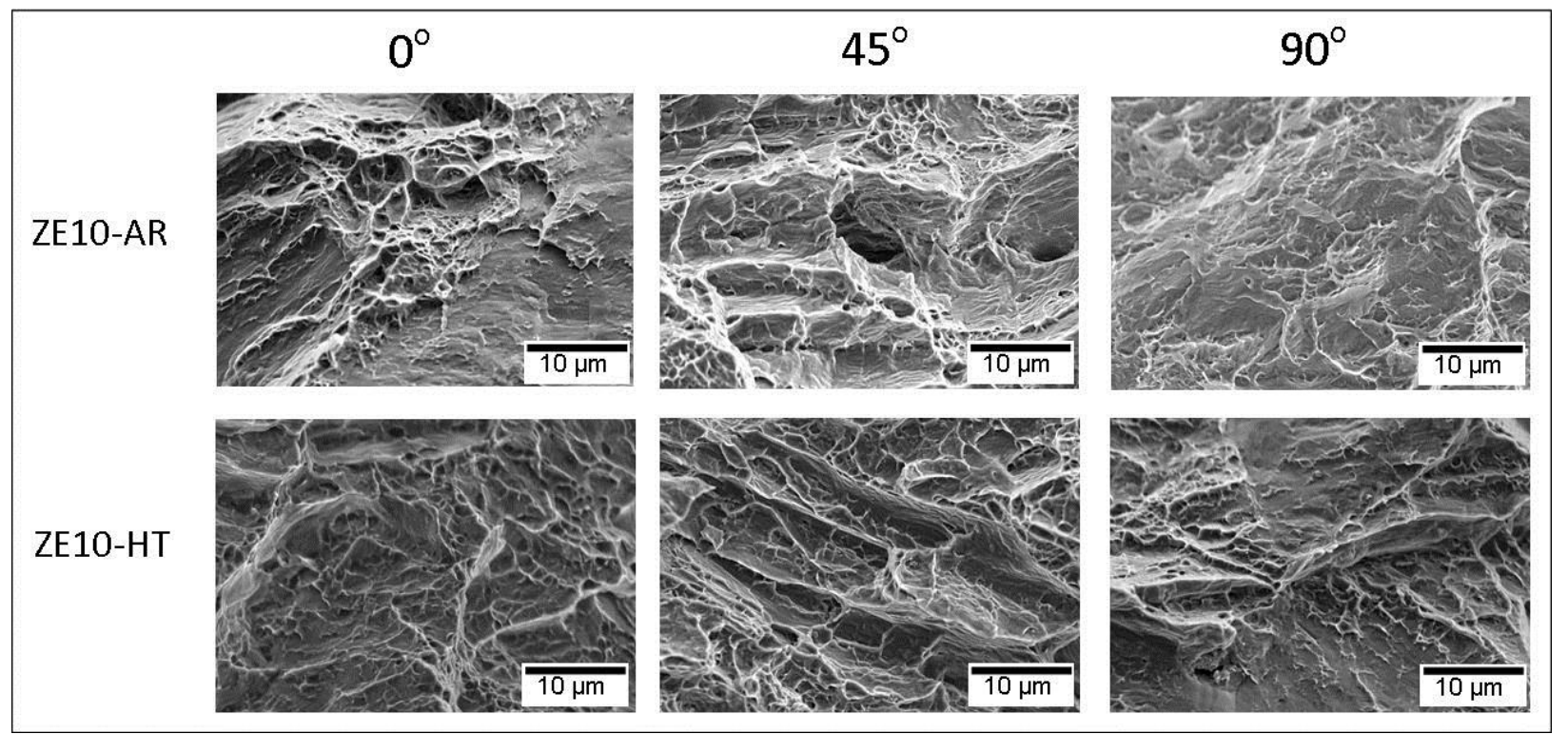

Fig. 7. Fracture surfaces of tensile tested samples of ZE10 materials in the as-received (AR) and heat treated (HT) conditions for three directions

\section{Summary}

The formability of two magnesium alloys, namely AZ80 and ZE10 has been investigated. Formability was assessed on the basis of the strain hardening exponent (n) and the plastic strain ratio ( $\mathrm{r}$ ) in the as-received and heat treated conditions. In addition, mechanical properties, such as yield and ultimate strength, elongation, stiffness and hardness were also measured for both conditions. Heat treatment was conducted at $410^{\circ} \mathrm{C}$ for one hour followed by water quenching.

In the as-received condition, the ZE10 alloy had a slightly better formability ( $\mathrm{r} \times \mathrm{n})$ than the AZ80 alloy, however, their treatment history were, arguably, different. The AZ80 most likely was supplied in the as-rolled, while ZE10 was received in an annealed condition. Following heat treatment, the formability of the AZ80 alloy was improved significantly. The microstructural analysis indicated that the heat treatment dissolved most of the precipitates and changed the grain structures i.e. got rid of deformed grains, dislocations and twins.

In the ZE10 case, based on microstructure analysis, both the as-received and the heat treated materials have similar grain structures except for a grain coarsening in the latter condition. The brief heat treatment process did not have a positive effect on formability of this alloy.

\section{References}

[1] Y. Liu, Y. Li, and W. Li, "Stamping formability of ZE10 magnesium alloy sheets," Journal of Rare Earths, vol. 25, p. 480-484, 2007.

[2] E. Doege and K. Dröder, "Sheet metal forming of magnesium wrought alloys - formability and process technology," Journal of Materials Processing Technology, vol. 115, p. 14-19, 2001.

[3] M. Marya, L. G. Hector, R. Verma, and W. Tong, "Microstructural effects of AZ31 magnesium alloy on its tensile deformation and failure behaviors," Materials Science and Engineering: A, vol. 418, p. 341-356, 2006.

[4] I. Yakubtsov, B. Diak, C. Sager, B. Bhattacharya, W. MacDonald, and M. Niewczas, "Effects of heat treatment on microstructure and tensile deformation of $\mathrm{Mg}$ AZ80 alloy at room temperature," Materials Science and Engineering: A, vol. 496, p. 247-255, 2008. 
[5] L. Stutz, J. Bohlenl, D. Letzigl, and K. U. Kainer, "Formability of magnesium sheet ZE10 and AZ31 with respect to initial texture," Magnesium Technology 2011, p. 373, 2011.

[6] S. Yi, J. Bohlen, F. Heinemann, and D. Letzig, "Mechanical anisotropy and deep drawing behaviour of AZ31 and ZE10 magnesium alloy sheets," Acta Materialia, vol. 58, p. 592-605, 2010.

[7] J. Bohlen, M. R. Nürnberg, J. W. Senn, D. Letzig, and S. R. Agnew, "The texture and anisotropy of magnesium-zinc-rare earth alloy sheets," Acta Materialia, vol. 55, p. 2101-2112, 2007.

[8] P. Wang, M. Lin, H. Lin, K. Lin, M. Yeh, and C. Lin, "Effects of aging treatment on microstructure and mechanical property of an AZ80N magnesium alloy," Materials Science and Engineering: A, vol. 527, p. 4076-4081, 2010.

[9] M. N. Mekonen, D. Steglich, J. Bohlen, D. Letzig, and J. Mosler, "Mechanical characterization and constitutive modeling of Mg alloy sheets," Materials Science and Engineering: A, vol. 540, p. 174-186, 2012.

[10] Mariusz Boba, Michael J. Worswicka, Raja Mishrab, Jon Carterb, "Formability of A31B and Zek100 Magnesium Alloy Sheets at Elevated Temperatures", in Mg2012: 9th International Conference on Magnesium Alloys and their Applications, W.J. Poole and K.U. Kainer (editors), p. 397-402, 2012.

[11] ASTM E646 Standard Test Method for Tensile Strain-Hardening Exponents (n-values) of Metallic Sheet Materials, 2007.

[12] ASTM E517 Standard Test Method for Plastic Strain Ratio (r), for Sheet Metal, 2010. 